\title{
TOLERÂNCIA DE FUNGOS ECTOMICORRÍZICOS E PLANTAS ASSOCIADAS A NÍVEIS TÓXICOS DE METAIS ${ }^{1}$
}

\author{
Bianca Lucchesi Targhetta ${ }^{2}$, Vetúria Lopes de Oliveira ${ }^{3}$ e Márcio José Rossi
}

\begin{abstract}
RESUMO - As ectomicorrizas são associações entre raízes de plantas e fungos, de grande importância para a sobrevivência e crescimento vegetal, por aumentar o aporte nutricional e a proteção contra fatores adversos. Os fungos ectomicorrízicos podem quelar íons de metais tóxicos, retirando-os do solo e diminuindo os danos ao hospedeiro. Quatro isolados de fungos ectomicorrízicos foram utilizados neste estudo: UFSC-Sc68 (Scleroderma sp.); UFSC-Ch163 (Chondrogaster angustisporus); UFSC-Pt116 e UFSC-Pt188 (Pisolithus microcarpus). Mudas de Eucalyptus dunnii foram testadas quanto à sua tolerância aos metais alumínio ( $\mathrm{Al})$, cádmio $(\mathrm{Cd})$, cromo $(\mathrm{Cr})$ e manganês $(\mathrm{Mn})$ misturados ao substrato de plantio, em dois experimentos em casa de vegetação. No primeiro, em ausência dos fungos e, no segundo, após inoculação com esses organismos. No experimento sem inoculação, o metal mais tóxico foi o Cr. Nenhuma planta sobreviveu nas doses 1000 e $10000 \mathrm{mg}^{\mathrm{k}} \mathrm{kg}^{-1} \mathrm{desse}$ metal. Para os outros metais, a matéria seca diminuiu com o aumento da dose. Já no estudo com plantas inoculadas, o Cd foi o metal mais tóxico, que reduziu significativamente a sobrevivência e o crescimento das plantas. Os isolados fúngicos UFSC-Pt188 e UFSC-Ch163 foram os mais eficientes na proteção contra os metais, melhorando a sobrevivência e a produção de matéria seca das plantas. O isolado UFSC-Ch163, em particular, foi o mais eficiente na tolerância das plantas, o que indica seu potencial de utilização em solos contaminados para favorecer o estabelecimento e o crescimento das plantas.
\end{abstract}

Palavras-chave: Biorremediação; Eucalipto; Contaminação do solo.

\section{TOLERANCE OF ECTOMYCORRHIZAL FUNGI AND PLANTS ASSOCIATED TO TOXIC LEVELS OF METALS}

\begin{abstract}
Ectomycorrhizas are associations between plant roots and fungi.They are very important for plant survival and growth since they increase nutrient uptake and protect plants against adverse conditions. Ectomycorrhizal fungi are able to chelate ions of toxic metals, removing them from the soil and reducing damages to the host. Four isolates of ectomycorrhizal fungi were used in this study: UFSC-Sc68 (Scleroderma sp.); UFSC-Ch163 (Chondrogaster angustisporus); UFSC-Pt116 and UFSC-Pt188 (Pisolithus microcarpus). Seedlings of Eucalyptus dunnii were tested for their response to aluminium (Al), cadmium (Cd), chromium $(\mathrm{Cr})$ and manganese $(\mathrm{Mn})$ mixed to the planting substrate in two experiments under greenhouse conditions. In the first experiment, in the absence of the fungi and, in the second experiment, after inoculation with those organisms. In the experiment with non-inoculated seedlings, Cr was the most toxic metal. No plant survived when submitted to 1.000 and $10.000 \mathrm{mg} . \mathrm{kg}^{-1}$ of this metal. Regarding the other metals, the dry matter decreased as the concentration was increased. In the experiment with inoculated seedlings, Cd was the most toxic metal, reducing significantly plant survival and growth. The isolates UFSC-Pt188 and UFSC-Ch163 were the most efficient in protecting plants against metals, improving the survival and the production of dry matter. The isolate UFSC-Ch163, particularly, was the most efficient in improving metal tolerance by the plants, indicating its potential for utilization in contaminated soils to promote plant survival and growth.
\end{abstract}

Keywords: Bioremediation; Eucalypt; Soil contamination.

\footnotetext{
${ }^{1}$ Recebido em 09.08.2012 aceito para publicação em 20.08.2013.

${ }^{2}$ Programa de Pós-Graduação em Biotecnologia e Biociências na Universidade Federal de Santa Catarina, UFSC, Brasil. E-mail:<bibalucchesi@gmail.com>.

${ }^{3}$ Universidade Federal de Santa Catarina, Departamento de Microbiologia, Imunologia e Parasitologia. E-mail:

<veturialopes@gmail.com>e <marcio@enq.ufsc.br>.
} 


\section{INTRODUÇÃO}

Dentre os diferentes tipos de micorrizas, as ectomicorrizas são de grande importância para o setor silvicultural. Essa associação simbiótica é particularmente importante para espécies dos gêneros Pinus e Eucalyptus, muito usadas nas indústrias de papel e celulose (ICEPA, 2004). Nessas plantas, a associação com fungos ectomicorrízicos aumenta a produtividade e reduz os gastos com adubação (BRUNDRETT et al., 1996; SOUZA et al., 2008). O micélio que se projeta externamente, a partir da raiz colonizada (micorriza), aumenta a área de contato com o solo e permite que maior quantidade de nutrientes e água sejam retirados do solo, incrementando seu aporte tanto para o fungo como para a planta (SMITH; READ, 2008).

Os fungos ectomicorrízicos produzem substâncias que inibem o crescimento de patógenos e protegem a planta contra doenças, e hormônios vegetais, que estimulam o crescimento e a ramificação das raízes. São capazes de armazenar metabólitos e nutrientes e funcionam, assim, como um sistema de reserva para situações de escassez nutricional ou crescimento ativo de ambos (SMITH; READ, 2008).

Alguns desses fungos podem quelar íons de metais no interior de suas células ou em exsudatos, retirando-os do solo e impedindo sua absorção pelas raízes. Dessa maneira, evitam ou diminuem a contaminação das plantas com metais, ao mesmo tempo em que contribuem para a remediação do solo. Além disso, foi demonstrado que algumas espécies de fungos podem acumular altas concentrações de metais em seus corpos de frutificação (TURNAU, 1991), ou em outros tecidos fúngicos, na parede celular e em compartimentos internos (COLPAERT; VAN ASSCHE, 1987; GADD, 1993; BLAUDEZ et al., 2000; GRAZZIOTTI et al., 2001; BELLION et al., 2006).

Os metais, na forma de íons solúveis no solo, são absorvidos pelas plantas e inibem o crescimento das raízes, diminuem a integridade das membranas biológicas e alteram o funcionamento normal das enzimas (KRUPA; KOZDRÓJ, 2004), prejudicando o desenvolvimento das plantas e a produção de madeira.

O acúmulo de alumínio acidifica o solo e restringe o crescimento das plantas. A incidência de chuva ácida acelera o processo de quebra dos minerais ricos em alumínio e a lixiviação dos cátions, empobrecendo o solo (MOYER-HENRY et al., 2005). Já o cádmio é um elemento não essencial, altamente tóxico. Sua presença é característica de áreas contaminadas com resíduos de mineração e de indústrias. O cromo é utilizado nas etapas de curtimento do couro e seu descarte contamina solos e cursos d'água. Da mesma maneira que o cádmio, o cromo é tóxico em pequenas quantidades (BLAUDEZ et al., 2000).

A indústria do couro é muito forte no oeste de Santa Catarina e a contaminação do solo e dos mananciais por cromo é muito comum. Em locais com atividade de mineração de carvão, como também é o caso de Santa Catarina, são comuns áreas de solo contaminadas com manganês (FUNGARO; IZIDORO, 2006) e com baixos valores de $\mathrm{pH}$ (COSTA; ZOCCHE, 2009). Sua recuperação pode ser obtida através da revegetação com plantas capazes de tolerar tais condições (BERRY, 1982; BECKJORD; McINTOSH, 1984; MEHARG; CAIRNEY, 2000; MEHARG, 2003).

Nesse contexto, este trabalho teve como objetivo selecionar isolados fúngicos ectomicorrízicos (fECM) com potencial para proteger as plantas em solos contaminados com níveis tóxicos de metais, contribuindo, assim, para a biorremediação dos solos e o aproveitamento de áreas contaminadas.

\section{MATERIAL E MÉTODOS}

\subsection{Obtenção e manutenção dos isolados de fungos ectomicorrízicos (fECM)}

Foram utilizados isolados de fECM, UFSC-Sc68 (Scleroderma sp.), UFSC-Ch163 (Chondrogaster angustisporus), UFSC-Pt116 e UFSC-Pt188 (Pisolithus microcarpus), previamente selecionados por sua eficiência na promoção do crescimento de Eucalyptus dunnii (SOUZA et al., 2004, 2008). Os três primeiros são provenientes de frutificações coletadas em plantações de E. dunnii, em Santa Catarina e o último é proveniente de plantações mistas de Eucalyptus spp., em Minas Gerais.

As culturas matrizes foram obtidas junto ao Laboratório de Ectomicorrizas da UFSC e foram repicadas para meio sólido Melin-Norkrans modificado (MNM) (MARX, 1969), em placas de Petri, e foram mantidos em incubadora BOD a $25 \pm 1{ }^{\circ} \mathrm{C}$, com repicagens periódicas durante o período experimental. 


\subsection{Crescimento de plantas de Eucalyptus dunnii em substrato contendo diferentes concentrações de metais, sob condições de casa de vegetação}

Os metais empregados foram alumínio, cádmio, cromo e manganês, nas concentrações $0,1,10,100$, 1000 e $10000 \mathrm{mg} \cdot \mathrm{kg}^{-1}$ de substrato de plantio. Esse substrato era uma mistura de turfa e vermiculita, na proporção de 1:3(V/V), submetido a dois ciclos de autoclavagem $\left(120^{\circ} \mathrm{C}\right.$ por $\left.60 \mathrm{~min}\right)$, num intervalo de $24 \mathrm{~h}$. Após esse processo, foi adubado com os seguintes nutrientes $\left(\mathrm{mg} \cdot \mathrm{pl}^{-1}\right): \mathrm{K}, 16 ; \mathrm{Mg}, 3 ; \mathrm{Mn}, 0,15 ; \mathrm{Cu}, 0,125$; Mo, 0,05; B, 0,05; Zn, 0,0375; Fe, 0,0375; P, 0,5; e N, 35; de acordo com Souza et al. (2004), e com a solução de cada metal, de modo a atingir as diferentes concentrações. Após secagem, o substrato foi misturado vigorosamente a fim de distribuir uniformemente os adubos e o metal.

Em seguida, o substrato foi distribuído em recipientes cônicos de PVC, de $60 \mathrm{~mL}$ de capacidade, previamente desinfetados com solução a $1 \%$ de hipoclorito de sódio, durante 12 horas e enxaguados. Cada um deles recebeu duas plântulas de Eucalyptus dunnii.

As sementes de Eucalyptus dunnii foram desinfetadas em álcool $70 \%$ por 30 s e lavadas três vezes em água destilada esterilizada. Em seguida, foram germinadas em solução estéril de ácido bórico ( $3 \mathrm{mM})$, glicose $\left(2\right.$ g.L $\left.\mathrm{L}^{-1}\right)$ e sulfato de cálcio $(500 \mathrm{mM}), \mathrm{pH} 5,7$, sob agitação durante 2-3 dias, à temperatura ambiente. Após germinação, foram lavadas com água destilada estéril e plantadas duas sementes germinadas em cada recipiente.

Utilizou-se um delineamento inteiramente casualizado, com um arranjo fatorial compreendendo quatro metais e seis doses, com cinco repetições por dose de metal, num total de 120 recipientes. O substrato semeado foi regado diariamente com água destilada. As plantas foram mantidas em casa de vegetação durante dois meses, com temperatura e umidade controladas. Durante o experimento, observou-se o crescimento e a aparência da parte aérea das plantas (coloração das folhas) e, ao término do período experimental, foi feita a avaliação da matéria seca. Os resultados foram submetidos à análise de variância e as médias comparadas pelo teste $\operatorname{LSD}(p \leq 0,05)$ utilizando-se o programa STATGRAPHICS ${ }^{\circledR}$.

\subsection{Efeito da associação entre Eucalyptus dunnii e fungos ectomicorrízicos, na sobrevivência e crescimento das plantas em substrato contaminado com metais, sob condições de casa de vegetação}

Com base nos resultados do experimento descrito no item anterior, foram selecionadas as doses de metais $0,10,100$ e $1000 \mathrm{mg} \cdot \mathrm{kg}^{-1}$, onde se verificou a capacidade dos isolados de fECM de contribuir para a resistência das plantas a esses níveis de metais. A dose de 10000 mg. $\mathrm{kg}^{-1}$ foi considerada muito tóxica para as plantas e não foi utilizada neste experimento.

A preparação dos materiais e a montagem deste experimento seguiram os mesmos procedimentos descritos para o experimento citado anteriormente, exceto no que diz respeito à germinação das sementes e à inoculação dos fungos ectomicorrízicos. A micorrização foi realizada in vitro em frascos de conserva contendo $50 \mathrm{~mL}$ de meio MNM semi-sólido (5\% de ágar), onde foram inoculados 2-3 discos de meio com micélio, previamente testados quanto à viabilidade e mantidos em incubação a $25 \pm 1{ }^{\circ} \mathrm{C}$ na obscuridade durante 15 dias.

As sementes foram desinfectadas em etanol $70 \%$ por $30 \mathrm{~s}$, e enxaguadas em água destilada estéril. Em seguida, foram imersas em solução de hipoclorito de sódio $1 \%$ por 20 min e lavadas três vezes em água destilada estéril. A germinação foi feita em meio sólido, contendo ácido bórico $(3 \mu \mathrm{M})$, glicose $\left(2 \mathrm{~g} . \mathrm{L}^{-1}\right)$, sulfato de cálcio $(500 \mu \mathrm{M})$, ágar $\left(4\right.$ g. $\left.\mathrm{L}^{-1}\right), \mathrm{pH} 5,7$, durante 7 dias na obscuridade. As plântulas foram transferidas para os frascos contendo o micélio fúngico, e mantidas por 1 mês em câmara de crescimento, com foto-período de 14 horas e intensidade luminosa variando de 28,53 $\mu \mathrm{mol} . \mathrm{s}^{-1} \cdot \mathrm{m}^{-2}$ a $36,83 \mu \mathrm{mol} . \mathrm{s}^{-1} \cdot \mathrm{m}^{-2}$.

O substrato de plantio com as doses dos metais, 0, 10, 100 e 1000 mg. $\mathrm{kg}^{-1}$, foi distribuído em recipientes cônicos de PVC de $60 \mathrm{~mL}$, previamente desinfetados. Utilizou-se um delineamento inteiramente casualizado, com um arranjo fatorial compreendendo os quatro metais, quatro doses e quatro isolados fúngicos, com três repetições para cada combinação dose de metal-fungo. Os recipientes foram distribuídos em bandejas de poliestireno e cada um recebeu duas plântulas de Eucalyptus dunnii colonizadas com fungos ectomicorrízicos, com as raízes colocadas a aproximadamente $1 \mathrm{~cm}$ de profundidade. As plantas foram mantidas durante dois meses em casa de vegetação 
e regadas diariamente com água destilada esterilizada. Após esse período, foram colhidas e analisadas quanto ao peso de matéria seca.

Os resultados foram submetidos à análise de variância e as médias comparadas pelo teste LSD $(p \leq 0,05)$ utilizando-se o programa STATGRAPHICS ${ }^{\circledR}$.

\section{RESULTADOS E DISCUSSÃO}

\subsection{Crescimento de plantas de Eucalyptus dunnii em substrato contendo diferentes concentrações de metais, sob condições de casa de vegetação}

$\mathrm{O}$ Cr foi o metal que mais afetou a sobrevivência e o crescimento das plantas. Nenhuma planta cresceu na dose de 1000 mg. $\mathrm{kg}^{-1}$. Na presença dos outros metais, o crescimento só foi inibido a $10000 \mathrm{mg} \cdot \mathrm{kg}^{-1}$. Na dose mais alta de $\mathrm{Mn}$, apenas uma planta sobreviveu, porém com peso de matéria seca muito baixo (Figura 1). A queda na produção de matéria seca das plantas, com o aumento da concentração do metal no substrato de plantio, seguiu um mesmo padrão para o Al, Cd e Mn. As plantas cultivadas em substrato com $\mathrm{Cr}$ tiveram um padrão de queda mais acentuado (Figura 1).

Observaram-se vários sintomas foliares que indicaram a toxicidade do metal para as plantas (BRUNDRETT et al., 1996). O metal que proporcionou maior variedade e intensidade de sintomas foi o $\mathrm{Cr}$, que causou clorose acentuada na dose $10 \mathrm{mg} . \mathrm{kg}^{-1}$, sendo esta mais intensa com o aumento da dose. O aparecimento desse sintoma foi precoce, logo que as primeiras folhas apareceram. O amarelecimento foi seguido de manchas

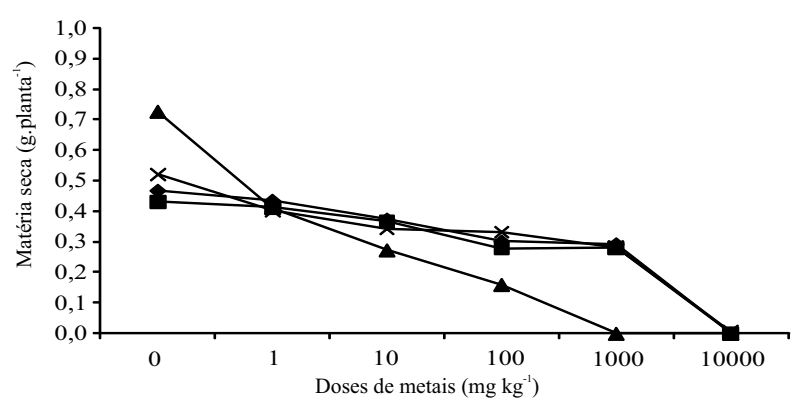

Figura 1 - Peso de matéria seca de mudas de Eucalyptus dunnii cultivadas em substrato contendo diferentes doses de metal, em condições de casa de vegetação. Alumínio

$(\downarrow)$, Cádmio (匹), Cromo (४) e Manganês (X).

Figure 1 - Plant dry matter of Eucalyptus dunnii growing in substrate containing different concentrations of metal, under greenhouse conditions. Aluminium ( $\bullet$, Cadmium $(\boldsymbol{\square})$, Chromium ( $\mathbf{\Delta})$ and Manganese (X). avermelhadas nas bordas foliares. Manchas vermelhas também apareceram já no tratamento a $1 \mathrm{mg} \cdot \mathrm{kg}^{-1}$ nas pontas das folhas. Nos tratamentos com Cd, a clorose só foi visível a partir de $100 \mathrm{mg} \cdot \mathrm{kg}^{-1}$. Porém, formaram-se manchas roxas espalhadas pelas folhas já nas menores doses. Na presença do Al, as plantas apresentaram manchas avermelhadas, bem como manchas amarelopálidas, a partir de $1 \mathrm{mg} . \mathrm{kg}^{-1}$, inclusive nas folhas mais jovens. As pontas das folhas do tratamento com 100 $\mathrm{mg} \cdot \mathrm{kg}^{-1}$ de Al apresentaram manchas que começaram a secar rapidamente. No tratamento com Mn, uma leve clorose teve início na dose de $10 \mathrm{mg} \cdot \mathrm{kg}^{-1}$, também com a presença de pequenas manchas avermelhadas. Acima de $100 \mathrm{mg} \cdot \mathrm{kg}^{-1}$, a clorose foi mais acentuada e as folhas mais novas já apresentavam leve coloração avermelhada na base e manchas amareladas espalhadas.

Sintomas de toxicidade e deficiência nutricional semelhantes aos deste estudo foram observados por Soares et al. (2005), que verificaram diminuição na altura de plantas de eucalipto e escurecimento das raízes com o aumento da dose de Cd. No estudo feito por Accioly et al. (2009) foram observados sintomas de toxidez muito semelhantes aos observados no presente estudo, que se agravaram com o aumento do tempo de exposição ao metal no solo.

\subsection{Efeito da associação entre Eucalyptus dunnii e fungos ectomicorrízicos, na sobrevivência e crescimento das plantas em substrato contaminado com metais, sob condições de casa de vegetação}

O crescimento das plantas também foi reduzido com o aumento da dose do metal, mas observou-se uma melhoria do crescimento, em termos de produção de matéria seca nos tratamentos inoculados. Esse efeito, porém, dependeu do isolado fúngico inoculado (Figuras 2 a 5$)$.

Corroborando os resultados do experimento descrito no item anterior, observou-se que os metais menos tóxicos para as plantas, tanto inoculadas quanto nãoinoculadas, foram o Al e o Mn. Nas plantas nãoinoculadas, o metal que mais afetou o crescimento foi o Cr, com os menores valores de peso de matéria seca. Nesse tratamento não inoculado, a dose de $100 \mathrm{mg} \cdot \mathrm{kg}^{-1}$ já foi suficiente para inibir totalmente a sobrevivência das plantas, colocando o $\mathrm{Cr}$ como o metal com a menor taxa de sobrevivência. No experimento anterior, o $\mathrm{Cr}$ também se destacou como o metal com maior efeito inibidor. 
Esse padrão modificou-se substancialmente com a inoculação das plantas com fungos ectomicorrízicos. Nos tratamentos inoculados, o Cd passou a ser o metal que provocou menor crescimento e sobrevivência. Dentre

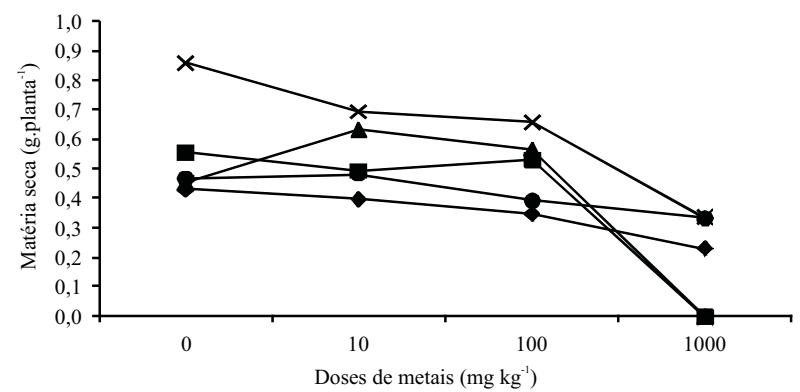

Figura 2 - Peso de matéria seca de mudas de Eucalyptus dunnii inoculadas com isolados de fungos ectomicorrízicos e cultivadas em substrato com diferentes doses de alumínio, em condições de casa de vegetação. Testemunha não inoculada ( $\bullet)$, UFSC-Sc68 (•), UFSC-Pt116 («), UFSC-Ch163 $(\mathrm{X})$ e UFSC-Pt188 (•).

Figure 2 - Plant dry matter of Eucalyptus dunnii seedlings, inoculated with ectomycorrhizal fungi isolates and cultivated in substrate containing different concentrations of aluminium, under greenhouse conditions. Non inoculated seedlings ( $\bullet$, UFSCSc68 (®), UFSC-Pt116 (^), UFSC-Ch163 (X) and UFSC-Pt188 (•).

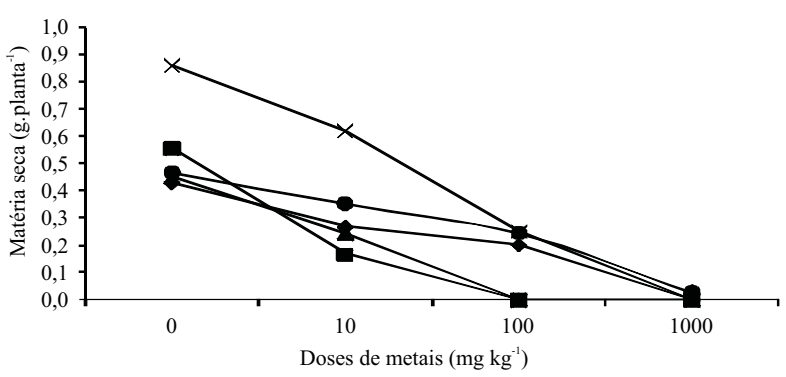

Figura 3 - Peso de matéria seca de mudas de Eucalyptus dunnii inoculadas com isolados de fungos ectomicorrízicos e cultivadas em substrato contendo diferentes doses de cádmio, em condições de casa de vegetação. Testemunha não inoculada ( $\bullet$, UFSCSc68 (•), UFSC-Pt116 (ム), UFSC-Ch163 (X) e UFSC-Pt188 $\bullet$ •).

Figure 3 - Plant dry matter of Eucalyptus dunnii seedlings, inoculated with ectomycorrhizal fungi isolates and cultivated in substrate containing different concentrations of cadmium, under greenhouse conditions. Non inoculated seedlings ( $\diamond), U F S C$ Sc68 (®), UFSC-Pt116 (^), UFSC-Ch163 (X) and UFSC-Pt188 (•). os tratamentos com inoculação, os isolados UFSCCh163 e UFSC-Pt188 foram aqueles que se destacaram, ao proporcionar maior sobrevivência e crescimento das plantas. As plantas inoculadas com o isolado UFSC-

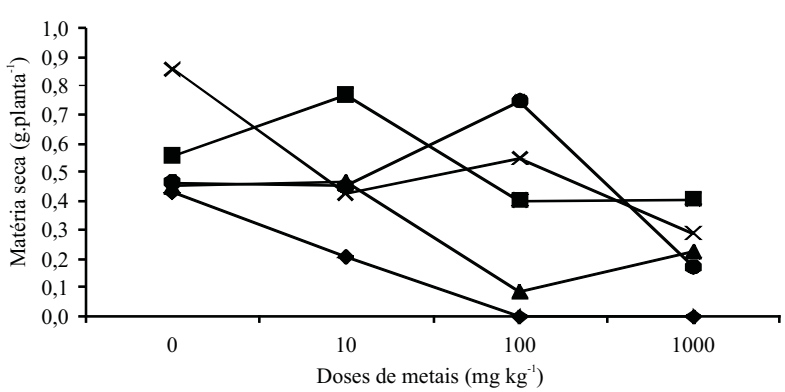

Figura 4 - Peso de matéria seca de mudas de Eucalyptus dunnii inoculadas com isolados de fungos ectomicorrízicos e cultivadas em substrato contendo diferentes doses de cromo, em condições de casa de vegetação. Testemunha não inoculada ( $\bullet$, UFSCSc68 (•), UFSC-Pt116 (4), UFSC-Ch163 (X) e UFSC-Pt188 $\bullet$ •).

Figure 4 - Plant dry matter of Eucalyptus dunnii seedlings, inoculated with ectomycorrhizal fungi isolates and cultivated in substrate containing different concentrations of chromium, under greenhouse conditions. Non-inoculated seedlings ( $\bullet), U F S C$ Sc68 (घ), UFSC-Pt116 (^), UFSC-Ch163 (X) and UFSC-Pt188 (•).

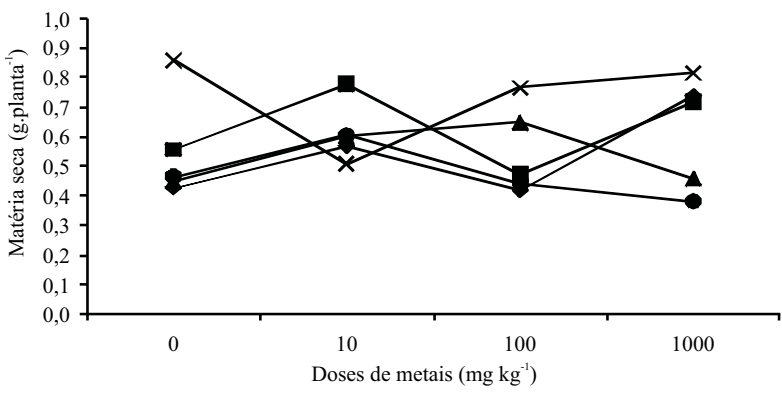

Figura 5 - Peso de matéria seca de mudas de Eucalyptus dunnii inoculadas com isolados de fungos ectomicorrízicos e cultivadas em substrato contendo diferentes doses de manganês, em condições de casa de vegetação. Testemunha não inoculada ( $\bullet)$, UFSC-Sc68 (•), UFSC-Pt116 («), UFSC-Ch163 $(\mathrm{X})$ e UFSC-Pt188 $(\bullet)$.

Figure 5 - Plant dry matter of Eucalyptus dunnii seedlings, inoculated with ectomycorrhizal fungi isolates and cultivated in substrate containing different concentrations of manganese, under greenhouse conditions. Non-inoculated seedlings ( $\bullet), U F S C$ Sc68 (®), UFSC-Pt116 (४) and UFSC-Ch163 (X) and e UFSC-Pt188 (•).

Revista Árvore, Viçosa-MG, v.37, n.5, p.825-833, 2013 
Ch163, em particular, apresentaram os maiores teores de matéria seca de todo o experimento. Em um estudo com Trema micrantha, inoculada com fungos micorrízicos arbusculares, Soares et al. (2007) verificaram que os sintomas de toxicidade causados por $\mathrm{Cd}$ eram amenizados pela interação simbiótica.

Para o tratamento com Al (Figura 2), a queda na produção de matéria seca foi menos acentuada, embora tenha havido uma redução com o aumento da dose. No tratamento inoculado com o isolado UFSC-Pt116, houve aumento na matéria seca quando a dose passou de 0 para 10 mg.kg- ${ }^{-1}$, com 0,452 g.planta ${ }^{-1}$ e 0,633 g.planta ${ }^{-1}$, respectivamente. Nas plantas inoculadas com o isolado UFSC-Sc68, ocorreu um ligeiro aumento na matéria seca na dose de $100 \mathrm{mg} . \mathrm{kg}^{-1}$. Na dose mais elevada desse metal (1000 mg.kg-1) não houve crescimento. A maior produção de matéria seca foi atingida pelo tratamento inoculado com o isolado UFSC-Ch163, que promoveu os maiores valores nessa variável em todas as doses exceto na dose $1000 \mathrm{mg} \cdot \mathrm{kg}^{-1} \mathrm{de} \mathrm{Al}$, onde a matéria seca do tratamento inoculado com esse isolado igualou-se à do tratamento inoculado com o isolado UFSC-Pt188.

A curva de matéria seca para o Cd (Figura 3) foi semelhante para todos os tratamentos de inoculação, mostrando uma queda mais acentuada com o aumento da dose do metal para o tratamento com o isolado UFSCSc68. Para o tratamento não-inoculado e o inoculado com o isolado UFSC-Ch163, não houve crescimento na dose de $1000 \mathrm{mg} . \mathrm{kg}^{-1}$. Para os tratamentos com os isolados UFSC-Sc68 e UFSC-Pt116 já não se observou crescimento a partir de $100 \mathrm{mg} \cdot \mathrm{kg}^{-1}$. O tratamento com o isolado UFSC-Ch163 se mostrou mais eficiente a 0 e $10 \mathrm{mg} \cdot \mathrm{kg}^{-1}$, ao promover maior produção de matéria seca.

Também para o Cr, a variação da produção de matéria seca foi semelhante. As plantas do tratamento testemunha, não-inoculadas, se mostraram bastantes sensíveis à presença deste metal, não tendo sido observado crescimento a partir da dose de $100 \mathrm{mg} \cdot \mathrm{kg}^{-1}$ (Figura 4).

As plantas dos tratamentos UFSC-Pt188 e UFSCPt1 16 apresentaram valores de matéria seca semelhantes nas duas menores doses ( 0 e $10 \mathrm{mg} \cdot \mathrm{kg}^{-1}$ ), porém, na dose de $100 \mathrm{mg} \cdot \mathrm{kg}^{-1}$, as plantas do tratamento com o isolado UFSC-Pt1 16 sofreram queda na produção de matéria seca enquanto as do tratamento UFSC-Pt188 apresentaram um ligeiro aumento. Para o tratamento
UFSC-Sc68, houve aumento na matéria seca na dose $10 \mathrm{mg} \cdot \mathrm{kg}^{-1}$, seguindo-se uma queda na dose seguinte. A partir desse ponto, a matéria seca permaneceu constante. As plantas desse tratamento de inoculação, apresentaram o maior valor de matéria seca nesta dose (1000 mg. $\left.\mathrm{kg}^{-1}\right)$, dentre todos os tratamentos. Já as plantas inoculadas com o isolado UFSC-Ch163, apresentaram queda na matéria seca com o aumento da dose de Cr já a partir de $10 \mathrm{mg} \cdot \mathrm{kg}^{-1}$.

O comportamento das plantas foi semelhante na presença de Mn, com aumento na produção de matéria seca na dose de $10 \mathrm{mg} \cdot \mathrm{kg}^{-1}$ e queda na dose de 100 mg.kg-1 (Figura 5). A matéria seca das plantas inoculadas com o isolado UFSC-Pt188 foi reduzida na dose de $1000 \mathrm{mg} \cdot \mathrm{kg}^{-1}$, já as plantas inoculadas com o isolado UFSC-Sc68 e as testemunhas não-inoculadas aumentaram a produção de matéria seca nessa dose. Houve aumento da matéria seca nas plantas inoculadas com o isolado UFSC-Pt1 16 nas doses de 10 mg.kg-1 e de 100 mg.kg-1 mas a produção diminuiu a $1000 \mathrm{mg} \cdot \mathrm{kg}^{-1}$. Para as plantas inoculadas com o isolado UFSC-Ch163, ocorreu queda na produção de matéria seca a $10 \mathrm{mg} \cdot \mathrm{kg}^{-1}$, seguindo-se um aumento nas doses seguintes. No caso desse isolado, o maior valor foi observado na dose mais alta $\left(1000 \mathrm{mg} \cdot \mathrm{kg}^{-1}\right)$, embora a diferença em relação à dose imediatamente inferior (100 mg. $\left.\mathrm{kg}^{-1}\right)$ não seja significativa (Figura 5).

Como no experimento do item 3.1., as plantas apresentaram sintomas de toxicidade, como manchas, perda foliar precoce e amolecimento, porém, de maneira geral, os sintomas apresentados foram menos graves. As plantas que não receberam metal mostraram-se saudáveis, sem sintomas de toxicidade.

$\mathrm{O}$ Cr causou manchas roxas e clorose, principalmente na dose de $1000 \mathrm{mg} \cdot \mathrm{kg}^{-1}$. No tratamento não-inoculado, apareceram grandes manchas roxas e as folhas começaram a secar. $\mathrm{O} \mathrm{Cd}$ provocou clorose e manchas roxas em todas as plantas, mesmo nas doses mais baixas. Esses sintomas foram mais acentuados nas plantas não-inoculadas e nas inoculadas com o isolado UFSCSc68. Em presença de Al, as plantas apresentaram clorose na dose $1000 \mathrm{mg} \cdot \mathrm{kg}^{-1}$ nos tratamentos com o isolado UFSC-Ch163 e na testemunha não-inoculada. No tratamento com o isolado UFSC-Pt116, as plantas apresentaram manchas roxas acentuadas na dose $100 \mathrm{mg} \cdot \mathrm{kg}^{-1}$. Nos demais tratamentos não foram observados sintomas de toxicidade pelo metal. $\mathrm{Na}$ 
presença do $\mathrm{Mn}$, as plantas inoculadas com os isolados UFSC-Sc68 e UFSC-Pt188 apresentaram manchas nas folhas e as mais antigas ficaram com uma coloração arroxeada nas doses $100 \mathrm{mg} \cdot \mathrm{kg}^{-1}$ e $1000 \mathrm{mg} \cdot \mathrm{kg}^{-1}$. Nesta última dose, também houve clorose. No tratamento não-inoculado ocorreram manchas roxas nas folhas antigas em todas as doses. A clorose esteve presente apenas nas plantas crescendo em 100 mg. $\mathrm{kg}^{-1}$ e 1000 mg.kg-1 . Já as plantas inoculadas com os isolados UFSCPt116 e UFSC-Ch163 apresentaram ligeira clorose apenas em presença da dose mais elevada desse metal.

As alterações de coloração das folhas em ambos os experimentos pareciam indicar deficiência nutricional causada pela presença do metal no substrato de plantio. De acordo com Brundrett et al. (1996), boa parte dos sintomas causados por deficiência nutricional é facilmente distinguível externamente, uma vez que cada deficiência produz alterações bem definidas. Para os eucaliptos esses sintomas são bem caracterizados, facilitando o trabalho em viveiros.

Utilizando-se a chave de Brundrett et al. (1996), e de acordo com os sintomas apresentados pelas plantas, observou-se que os metais causaram deficiência de nitrogênio $(\mathrm{N})$, enxofre $(\mathrm{S})$, potássio $(\mathrm{K})$, fósforo $(\mathrm{P})$, cálcio $(\mathrm{Ca})$ e ferro $(\mathrm{Fe})$. Destes, os cinco primeiros são macronutrientes e o último é um micronutriente. Isso explica a queda acentuada na produção de matéria seca nas maiores doses de metais. Os sintomas de deficiência foram mais acentuados nas doses mais elevadas de $\mathrm{Cd}$ e $\mathrm{Cr}$, e mostram que esses dois metais afetam mais intensamente o aporte nutricional das plantas e dos fungos. Segundo Shanker et al. (2005), a toxicidade do $\mathrm{Cr}$ em plantas está relacionada à baixa produção, inibição de crescimento de folhas e raízes, inibição de atividades enzimáticas e mutagênese. De acordo com o estudo de Accioly et al. (2009), os sintomas apresentados pelas mudas de E. camaldulensis foram caracterizados pela deficiência de $\mathrm{Fe}$, sugerindo a interferência dos metais no aporte deste elemento. De maneira geral, o Cd interfere no aporte, transporte e uso de diferentes elementos (Ca, P, K e Mg) e também da água (DAS et al., 1997).

Outro ponto importante a ser considerado é que apesar de os sintomas apresentados terem relação direta com a deficiência nutricional, os minerais essenciais foram aplicados de maneira correta e na dose recomendada por estudo anterior (SOUZA et al., 2004), indicando que os metais interferem no aporte e na utilização dos nutrientes pela planta.

Considerados em seu conjunto, os resultados indicam que a inoculação com fungos ectomicorrízicos promove uma melhor sobrevivência e melhor crescimento das plantas. Essa melhoria foi notadamente mais acentuada nas plantas inoculadas com os isolados UFSC-Ch163 e UFSC-Pt188. A tolerância de fungos ectomicorrízicos à presença de metais tóxicos no solo e em meios de cultura tem sido amplamente demonstrada, embora os mecanismos de ação ainda não estejam completamente esclarecidos (COLPAERT; VANASSCHE, 1992a, b; HARTLEY-WHITAKER et al., 2000; KRUPA; KOZDRÓJ, 2004; MOYER-HENRY et al., 2005).

Os mecanismos de proteção podem ser divididos em dois grupos, de acordo com a localização, sendo os extracelulares (quelação, ligação à parede celular e controle de fluxo) mais relacionados à resistência e os intracelulares (ligação a metalotioneínas, melaninas e compartimentalização) relacionados ao fenômeno da tolerância (BELLION et al., 2006). Entretanto, esses mecanismos não podem ser generalizados, pois dependem da espécie fúngica e do metal tóxico. Raramente há um único metal poluindo o solo, o que dificulta o entendimento de cada processo separadamente. As interações entre os fungos podem alterar a maneira como os metais serão absorvidos ou imobilizados e, também, a interação entre os diferentes metais pode torná-los mais ou menos disponíveis (WILKINS, 1991; COLPAERT; VAN ASSCHE, 1992b; WILKINSON; DICKINSON, 1995; ANDERSON; CAIRNEY, 2007).

Para o isolado UFSC-Ch163, a eficiência na proteção das plantas em relação a todos os metais testados pode indicar que o mecanismo para detoxificação não seja metal-específico. Este isolado foi aquele que apresentou maior eficiência na proteção das plantas contra o alumínio, o cádmio e o manganês, considerando-se a produção de matéria seca das plantas. Quanto ao isolado UFSCPt116, sabe-se que ele produz grande quantidade de pigmentos em cultura (ROSSI et al., 2002), possivelmente melânicos, o que poderia permitir seu crescimento em doses elevadas dos metais. Os isolados UFSC-Sc68 e UFSC-Pt1 88 também produzem grande quantidade de pigmentos, que poderiam colaborar em sua capacidade de detoxificação.

Esses resultados mostram que esse tipo de associação ectomicorrízica pode ser utilizada para ajudar 
o estabelecimento de vegetação em solos contaminados com metais. É uma estratégia menos danosa ao meio ambiente por poder permitir a revegetação e a manutenção da microbiota do solo, o que contribuiria para o processo de descontaminação do solo.

\section{CONCLUSÕES}

- Plantas de Eucalyptus dunnii, quando associadas a fungos ectomicorrízicos, apresentam maior sobrevivência e crescimento em substrato contaminado com metais.

-Os isolados UFSC-Ch163 eUFSC-Pt188 apresentaram a maior eficiência no aumento de produção de matéria seca das plantas nas diferentes doses e diferentes metais.

\section{AGRADECIMENTOS}

Este estudo foi parcialmente financiado com recursos do Conselho Nacional de Desenvolvimento Científico e Tecnológico. (CNPq). Ao Dr. Eduardo Cargnin Ferreira por seus valiosos comentários na discussão dos resultados. À RIGESA, Celulose, Papel e Embalagens Ltda., Três Barras, SC, pelo fornecimento das sementes de eucalipto.

\section{REFERÊNCIAS}

ACCIOLY, A. M. A.; SOARES, C. R. F. S.; SIQUEIRA, J. O. Silicato de cálcio como amenizante da toxidez de metais pesados em mudas de eucalipto. Pesquisa Agropecuária Brasileira, v.44, n.2, p.180-188, 2009.

ANDERSON, I. C.; CAIRNEY, J. W. G. Ectomycorrhizal fungi: exploiting the mycelial frontier. FEMS Microbiology Reviews, v.31, n.4, p.388-406, 2007.

BECKJORD, P. R.; McINTOSH, M. S. Growth and field persistence by Quercus rubra inoculated with ectomycorrhizal fungi and planted on a clearcutting and strip mine. Canadian Journal of Botany, v.63, p.1571-1574, 1984.

BELLION, M. et al. Extracellular and cellular mechanisms sustaining metal tolerance in ectomycorrhizal fungi. FEMS Microbiology Letters, v.254, n.2, p.173-181, 2006.

BERRY, C. R. Survival and growth of pine hybrid seedlings with Pisolithus ectomycorrhizae on coal spoils in Alabama and Tenessee. Journal of Environmental Quality, v.11, p.709-715, 1982.
BLAUDEZ, D.; BOTTON, B.; CHALOT, M. Cadmium uptake and subcellular compartimentation in the ectomychorrhizal fungus Paxillus involutus. Microbiology-UK, v.146, p.1109-1117, 2000.

BRUNDRETT, M. et al. Working with mycorrhizas in forestry and agriculture. Canberra: ACIAR, 1996. 374 p. (Monograph, 32)

COLPAERT, J. V.; van ASSCHE, J. A. Heavy metal tolerance in some ectomycorrhizal fungi.

Functional Ecology, v.1, n.4, p.415-421, 1987.

COLPAERT, J. V.; van ASSCHE, J. A. The effects of cadmium and the cadmium-zinc interaction on the axenic growth of ectomycorrhizal fungi.

Plant and Soil, v.145, n.2, p.237-243, 1992 a.

COLPAERT, J. V.; van ASSCHE, J. A. Zinc toxicity in ectomycorrhizal Pinus sylvestris. Plant and Soil, v.143, n.2, p.201-211, 1992b.

COSTA, S.; ZOCCHE, J. J. Fertilidade de solos construídos em áreas de mineração de carvão na região sul de Santa Catarina. Revista Árvore, v.33, n.4, p.665-674, 2009.

DAS, P.; SAMANTARAY, S.; GOUT, G. R. Studies on cadmium toxicity in plants: A review.

Environmental Pollution, v.98, n.1, p.2936, 1997.

FUNGARO, D. A.; IZIDORO, J. C. Remediação de drenagem ácida de mina usando zeólitas sintetizadas a partir de cinzas leves de carvão. Química Nova, v.29, n.4, p.735-740, 2006.

GADD, G. M. Interactions of fungi with toxic metals. New Phytologist, v.124, n.1, p.25-60, 1993.

GRAZZIOTTI, P. H. et al. Tolerância de fungos ectomicorrízicos a metais pesados em meio de cultura adicionado de solo contaminado.

Revista Brasileira de Ciência do Solo, v.25, n.4, p.839-848, 2001.

HARTLEY-WHITAKER, J.; CAIRNEY, J. W. G.; MEHARG, A. A. Toxic effects of cadmium and zinc in ectomycorrhizal colonization of scots pine (Pinus sylvestris L.) from soil inoculum. Environmental Toxicology and Chemistry, v.19, n.3, p.694-699, 2000. 


\author{
INSTITUTO DE PLANEJAMENTO E ECONOMIA \\ AGRÍCOLA DE SANTA CATARINA - ICEPA. \\ Desempenho do Setor Florestal. In: SÍNTESE \\ ANUAL DAAGRICULTURA DE SANTA \\ CATARINA - 2002-2003. Florianópolis: Instituto \\ CEPA/SC, 2004. p.164-184.
}

KRUPA, P.; KOZDRÓJ, J. Accumulation of heavy metals by ectomycorrhizal fungi colonizing birch trees growing in an industrial desert soil. World Journal of Microbiology and

Biotechnology, v.20, n.4, p.427-430, 2004.

MARX, D. H. The influence of ectotrophic mycorrhizal fungi on the resistance of pine roots to pathogenic infections. I. Antagonism of mycorrhizal fungi to root pathogenic fungi and soil bacteria. Phytopathology, v.59, n.2, p.153163, 1969.

MEHARG, A. A.; CAIRNEY, J. W. G.

Ectomycorrhizas - extending the capabilities of rhizosphere remediation? Soil Biology \&

Biochemistry, v.32, n.11, p.1475-1484, 2000.

MEHARG, A. A. The mechanistic basis of interactions between mycorrhizal associations and toxic metal cations. Mycological Research, v.107, n.11, p.1253-1265, 2003.

MOYER-HENRY, K. et al. Accumulation and localization of aluminium in root tips of loblolly pine seedlings and the associated ectomycorrhiza Pisolithus tinctorius. Plant, Cell and Environment, v.28, n.2, p.111-120, 2005.

ROSSI, M. J.; SOUZA, J.A.R.; OLIVEIRA, V. L. Inoculum production of the ectomycorrhizal fungus Pisolithus microcarpus in an airlift bioreactor. Applied Microbiology and Biotechnology, v.59, p.175-181, 2002.
SHANKER, A. R. et al. Chromium toxicity in plants. Environment International, v. 31 , n.5, p.739-753, 2005.

SMITH, S. E.; READ, D. J. Mycorrhizal symbiosis, London: Academic Press, 2008. 787p.

SOARES, C. R. F. S. et al. Fitotoxidez de cádmio para Eucalyptus maculata e E. urophylla em solução nutritiva. Revista Árvore, v.29, n.2, p.175-183, 2005.

SOARES, C. R. F. S. et al. Nutrição fosfática e micorriza arbuscular na redução da toxicidade de cádmio em trema [Trema micrantha (L.) Blum.]. Revista Árvore, v.31, n.5, p.783-792, 2007.

SOUZA, L. A. B. et al. New isolates of ectomycorrizal fungi and the growth of eucalypt. Pesquisa Agropecuária Brasileira, v.43, n.2, p.235-241, 2008.

SOUZA, L. A. B.; SILVA FILHO, G. N.; OLIVEIRA, V. L. Eficiência de fungos ectomicorrízicos na absorção de fósforo e na promoção do crescimento de eucalipto. Pesquisa Agropecuária Brasileira, v.39, n.4, p.349$355,2004$.

TURNAU, K. The influence of cadmium dust on fungi in a Pino-Quercetum forest. Ekologia Polska, v.39, n.1, p.39-57, 1991.

WILKINS, D. A. The influence of sheathing (ecto-) mycorrhizas of trees on the uptake and toxicity of metals. Agriculture, Ecosystems and Environment, v.35, n.2/3, p.245-260, 1991.

WILKINSON, D. M.; DICKINSON, N. M. Metal resistance in trees: the role of mycorrhizae. Oikos, v.72, n.2, p.298-300, 1995. 
